\title{
How partial reinforcement of food cues affects the extinction and reacquisition of appetitive responses: a new model for dieting success?
}

Citation for published version (APA):

van den Akker, K., Havermans, R. C., Bouton, M. E., \& Jansen, A. (2014). How partial reinforcement of food cues affects the extinction and reacquisition of appetitive responses: a new model for dieting success? Appetite, 81, 242-252. https://doi.org/10.1016/j.appet.2014.06.024

Document status and date:

Published: 25/06/2014

DOI:

10.1016/j.appet.2014.06.024

Document Version:

Publisher's PDF, also known as Version of record

Document license:

Taverne

Please check the document version of this publication:

- A submitted manuscript is the version of the article upon submission and before peer-review. There can be important differences between the submitted version and the official published version of record.

People interested in the research are advised to contact the author for the final version of the publication, or visit the DOI to the publisher's website.

- The final author version and the galley proof are versions of the publication after peer review.

- The final published version features the final layout of the paper including the volume, issue and page numbers.

Link to publication

\footnotetext{
General rights rights.

- You may freely distribute the URL identifying the publication in the public portal. please follow below link for the End User Agreement:

www.umlib.nl/taverne-license

Take down policy

If you believe that this document breaches copyright please contact us at:

repository@maastrichtuniversity.nl

providing details and we will investigate your claim.
}

Copyright and moral rights for the publications made accessible in the public portal are retained by the authors and/or other copyright owners and it is a condition of accessing publications that users recognise and abide by the legal requirements associated with these

- Users may download and print one copy of any publication from the public portal for the purpose of private study or research.

- You may not further distribute the material or use it for any profit-making activity or commercial gain

If the publication is distributed under the terms of Article $25 \mathrm{fa}$ of the Dutch Copyright Act, indicated by the "Taverne" license above, 
Research report

\title{
How partial reinforcement of food cues affects the extinction and reacquisition of appetitive responses. A new model for dieting success?
}

\author{
Karolien van den Akker ${ }^{\mathrm{a}, *}$, Remco C. Havermans ${ }^{\mathrm{a}}$, Mark E. Bouton ${ }^{\mathrm{b}}$, Anita Jansen ${ }^{\mathrm{a}}$ \\ a Faculty of Psychology and Neuroscience, Department of Clinical Psychological Science, Maastricht University, P.O. Box 616, 6200 MD Maastricht, The \\ Netherlands \\ ${ }^{\mathrm{b}}$ Department of Psychology, University of Vermont, 2 Colchester Ave., Burlington, VT 05405-0134, USA
}

\section{A R T I C L E I N F O}

\section{Article history:}

Received 20 January 2014

Received in revised form 12 May 2014

Accepted 18 June 2014

Available online 25 June 2014

\section{Keywords:}

Appetitive conditioning

Dieting success

Unsuccessful dieting

Partial reinforcement

Impulsivity

Extinction

\begin{abstract}
A B S T R A C T
Animals and humans can easily learn to associate an initially neutral cue with food intake through classical conditioning, but extinction of learned appetitive responses can be more difficult. Intermittent or partial reinforcement of food cues causes especially persistent behaviour in animals: after exposure to such learning schedules, the decline in responding that occurs during extinction is slow. After extinction, increases in responding with renewed reinforcement of food cues (reacquisition) might be less rapid after acquisition with partial reinforcement. In humans, it may be that the eating behaviour of some individuals resembles partial reinforcement schedules to a greater extent, possibly affecting dieting success by interacting with extinction and reacquisition. Furthermore, impulsivity has been associated with less successful dieting, and this association might be explained by impulsivity affecting the learning and extinction of appetitive responses. In the present two studies, the effects of different reinforcement schedules and impulsivity on the acquisition, extinction, and reacquisition of appetitive responses were investigated in a conditioning paradigm involving food rewards in healthy humans. Overall, the results indicate both partial reinforcement schedules and, possibly, impulsivity to be associated with worse extinction performance. A new model of dieting success is proposed: learning histories and, perhaps, certain personality traits (impulsivity) can interfere with the extinction and reacquisition of appetitive responses to food cues and they may be causally related to unsuccessful dieting.
\end{abstract}

(c) 2014 Elsevier Ltd. All rights reserved.

\section{Introduction}

As obesity prevalence continues to rise, so do attempts to lose weight by restricting dietary intake (Hill, 2002). In a US sample, as many as $60 \%$ of overweight and $70 \%$ of obese women reported to be currently trying to lose weight (Bish et al., 2005). However, successful long-term weight loss is rare, and weight loss practises have even been linked to binge eating, weight gain and the development of obesity (e.g., Field et al., 2003; Jeffery et al., 2000; Neumark-Sztainer et al., 2006; Stice, Presnell, Shaw, \& Rohde, 2005). Learning models can help explain why successful long-term weight loss is so difficult (Bouton, 2011; Jansen, 1998). After conditioned

\footnotetext{
Acknowledgements: The authors would like to thank Jacco Ronner for technical assistance. This study is part of an ongoing project that is financed by the Netherlands Organisation for Scientific Research (NWO): Vici Grant 453.10.006, awarded to Anita Jansen.

* Corresponding author.

E-mail address: karolien.vandenakker@maastrichtuniversity.nl (K. van den Akker).
}

stimuli (CSs) have become associated with food intake (unconditioned stimulus; US), they will elicit conditioned responses (CRs). Exposure to a CS can induce (strong) desires for food, and may promote food consumption (e.g., Boggiano, Dorsey, Thomas, \& Murdaugh, 2009; Jansen, 1998).

Conditioning phenomena could also explain why some dieters are able to adhere to their diets more successfully than others. Intermittent reinforcement of conditioned food cues (i.e., the alternation of intake and restriction in response to food cues) has long been known to result in persistent conditioning effects in animals. For instance, rats that do not always receive a food US when presented with a CS (e.g., on 50\% of the trials) are known to perform worse in an extinction training in which the CS is never followed anymore by the US, compared with rats that had received a $100 \%$ contingency conditioning procedure (e.g., Bouton, Woods, \& Todd, 2014; Haselgrove, Aydin, \& Pearce, 2004). Thus, paradoxically, although the reinforcement schedule is leaner in rats receiving partial (e.g., $50 \%$ contingency) instead of continuous (100\% contingency) reinforcement, extinction is more difficult. This difficulty to extinguish conditioned responses after partial reinforcement is known 
as the partial reinforcement extinction effect (PREE). It is thought that the PREE occurs because, in case of partial reinforcement, the animal has received reward under conditions of nonreinforcement: extinction is harder to achieve because a nonreinforced CS signals possible US availability on the next trial (e.g., Amsel, 1962; Capaldi, 1994). Consequently, reward is expected after nonreinforced CS trials during extinction and appetitive responses are more persistent. Further, it can be argued that original learning with either continuous or partial reinforcement might result in differential response patterns when the CS-US contingency is again reinforced after extinction, i.e. during a reacquisition phase. Reacquisition after extinguished responses to a continuous schedule is often rapid (e.g., Ricker \& Bouton, 1996); however, one might expect that the return of appetitive responses during reacquisition after extinction is less pronounced after partial reinforcement because a reinforced CS does not predict (as strongly) that the subsequent trial will be reinforced.

It seems likely that there are intra- and inter-individual differences in the extent to which food cues are reinforced, and thus, the extent to which partial reinforcement is practised. For instance, an individual might consume breakfast at a relatively similar timepoint every day while less consistently eating a snack in the afternoon, alternating 'eating' and 'not eating' on a day-to-day basis for some cues. Over time, the predominant learning schedule for inconsistently reinforced food cues essentially reflects partial reinforcement schedules. Additionally, across individuals, it seems likely that overall patterns of reinforcement differ: some may practise partial reinforcement to a greater extent than others. For instance, some individuals may show a relatively inconsistent eating pattern, reinforcing and nonreinforcing different sets of cues each day (e.g., Kirk \& Hill, 1997). When an individual starts a diet, extinction is presumably practised because he or she is attempting to refrain from eating (US) in response to previously reinforced cues (CS). The PREE would predict that this extinction is more difficult to achieve for those who previously practised a greater degree of partial reinforcement. A more difficult extinction of conditioned responses would theoretically result in a greater difficulty to refrain from eating in response to those cues: during extinction of previously partially reinforced cues, a dieter's body keeps expecting to receive food in response to such cues (i.e., they experience PREEs). Thus, the dieter could experience heightened conditioned cravings for foods even after a period in which he or she has suppressed responses to the cues. However, when a dieter has successfully extinguished these responses and thus has overcome the PREE, one could expect that a history of partial reinforcement could be beneficial for longterm weight maintenance. Since returns of appetitive responses after extinction ('relapse') are thought to considerably thwart dieting efforts (Bouton, 2011), a history of partial reinforcement could decrease chances for a full-blown relapse because they may slow down reacquisition. To gain insight into the underlying mechanisms behind individual differences in dieting success, examining causes of potential differences in the extinction and reacquisition of appetitive responses could prove valuable.

Apart from learning histories, personality characteristics could also affect dieting success. Impulsivity has been especially associated with increased cue reactivity, overeating, and obesity (Guerrieri, Nederkoorn, \& Jansen, 2008; Tetley, Brunstrom, \& Griffiths, 2010). Importantly, impulsivity has been found to distinguish successful from less successful dieters - impulsivity has been related to less weight loss during a weight loss treatment (e.g., Nederkoorn, Jansen, Mulkens, \& Jansen, 2007), less successful self-reported dieting (e.g., van Koningsbruggen, Stroebe, \& Aarts, 2013), and in the lab, restrained eaters (dieters) only overate when they were also impulsive (Jansen et al., 2009). Also, it seems that impulsiveness increases the risk for relapse in addicts (e.g., Doran, Spring, McChargue, Pergadia, \& Richmond, 2004), and evidence suggests that treat- ment outcome and maintenance could be improved by targeting impulsivity (Houben \& Jansen, 2011; Houben, Wiers, \& Jansen, 2011; Verbeken, Braet, Goossens, \& van der Oord, 2013). It is possible that a relationship between impulsivity and unsuccessful dieting could be explained by differences in the learning and 'unlearning' of conditioned responses to rewarding cues between more and less impulsive individuals. For instance, different aspects of impulsivity have been theoretically associated with an increased speed of acquisition of appetitive responses, although empirical tests have been inconclusive (Corr, 2001, 2002; Corr, Pickering, \& Gray, 1995; Dawe, Gullo, \& Loxton, 2004; Gorenstein \& Newman, 1980; Papachristou, Nederkoorn, Beunen, \& Jansen, 2013; Patterson \& Newman, 1993; van den Akker, Jansen, Frentz, \& Havermans, 2013). Further, one specific aspect of impulsivity, rash impulsiveness or the inability to inhibit predominant approach responses (as measured by the BIS11) (Dawe et al., 2004; Patton, Stanford, \& Barratt, 1995) could be associated with impaired extinction. The underlying neural structure of rash impulsiveness is the orbitofrontal cortex (OFC): worse functioning of the OFC has been related to higher rash impulsiveness in healthy individuals (see Dawe et al., 2004; Horn, Dolan, Elliott, Deakin, \& Woodruff, 2003). Investigations in rodents, monkeys, and humans have resulted in the conclusion that the OFC is necessary for integrating changing information about a reward and providing new estimations about expected outcomes, that is, learning when reward contingencies change (e.g., Butter, 1969; Gallagher, McMahan, \& Schoenbaum, 1999; McDannald, Jones, Takahashi, \& Schoenbaum, 2014; Rolls, 2000, 2004; Schoenbaum \& Esber, 2010; Schoenbaum, Roesch, Stalnaker, \& Takahashi, 2009). A relatively poor functioning OFC in rash impulsive individuals could therefore result in less correct estimates of expected outcomes when CS-US contingencies are altered during extinction, i.e. resulting in extinction deficits. The present studies investigate whether a measure of rash impulsiveness influences the acquisition and extinction of appetitive responses.

In sum, dieters who previously practised intermittent reinforcement of food cues might be less successful in restricting their food intake through difficulties in achieving extinction (i.e., they might experience a PREE), while simultaneously being at reduced risk for relapse once extinction has been achieved. However, relatively few human appetitive conditioning studies involving food rewards have been conducted (e.g., Van Gucht, Vansteenwegen, Beckers, \& Van den Bergh, 2008), and none examined effects of partial reinforcement on conditioned responses to food cues. The present two studies were designed to test the hypothesis that an appetitive partial reinforcement schedule causes a PREE in healthy humans and slows down a return of appetitive responses when CSs are reinforced again after extinction. Since impulsivity has theoretically been associated with a possibly faster acquisition of conditioned appetitive responses and slower extinction, the influence of impulsivity on the different phases of conditioning was also investigated.

\section{Study 1}

\section{Methods and materials}

\section{Participants}

Thirty-two participants took part in the study. Three participants did not develop a differential US expectancy, suggesting they were not aware of the CS-US contingency. They were replaced by three other participants ensuring full counterbalancing. All participants were undergraduate female students who were proficient in Dutch and indicated a liking for chocolate. Participants were instructed to have a small meal two hours prior to participation but to refrain from calorie intake thereafter. To reduce demand characteristics participants were told the study's aim was to investigate the memory of taste. Participants received either $€ 7.50$ or 
course credit for participation. A local ethical committee approved the study.

\section{Measurements}

Desire and US expectancy. $100 \mathrm{~mm}$-Visual Analogue Scales (VAS) were used to assess subjective desire for chocolate mousse ('How strong is your desire for chocolate mousse at this moment?') and expectancy to taste chocolate mousse ('How strong do you expect to receive chocolate mousse at this moment?'). Ratings ranged from 0 (no desire at all/certainly expect not to taste chocolate mousse) to 100 (very strong desire/certainly expect to taste chocolate mousse). The order of presentation of these two questions was counterbalanced.

Salivation. Salivation was measured using dental rolls (Hartmann, $\mathrm{nr} 2,10 \times 35 \mathrm{~mm}$ ) which the participant placed and removed herself. Two dental rolls were placed between the cheek and lower gum on the left and right sides. They were removed after precisely $1 \mathrm{~min}$. The dental rolls were kept in a sealed plastic bag and their weight was registered before and after the saliva was collected, using a weighing scale accurate to $0.01 \mathrm{~g}$ (Mettler Toledo, PB3002).

$\mathrm{CS}$ preference. After the experiment, participants indicated their CS preference (CS+ or CS-) ('If you were allowed to take one of the boxes home, which one would you pick?').

Hunger: To control for hunger, participants filled in a VAS ('How hungry are you at this moment?') ranging from 0 (not hungry at all) to 100 (extremely hungry) before and after the conditioning procedure.

Chocolate mousse liking. To control for differences in the liking of chocolate mousse, participants filled in a VAS ('How much did you like the chocolate mousse?') ranging from 0 (not at all) to 100 (extremely).

Barrett impulsivity scale-11 (BIS-11; Patton et al., 1995). The BIS11 was used to measure impulsivity. The BIS-11 is a self-report questionnaire and consists of 30 items. Each statement can be rated on a 4-point scale, ranging from rarely/never to always/almost always. Total scores were calculated, a higher score indicating higher impulsiveness. The BIS-11 has good internal consistency and is well validated (Patton et al., 1995; Stanford et al., 2009). The internal consistency of the total BIS-11 score in the current studies was good (Cronbach's alpha of study 1:.79; study 2:.90).

Revised restraint scale (RS; Polivy, Herman, \& Howard, 1988). To control for differences in dietary restraint (i.e. the intention to restrict food intake) the 10 -item RS was used. Scores range from 0 to 35 , a higher score indicating increased intentions to restrain intake. The RS is thought to be a reliable measure of dieting (Lowe \& Thomas, 2009).

All questionnaires were administered in Dutch.

\section{Stimuli}

US. A small portion of chocolate mousse (approximately $2 \mathrm{~g}$, Almhof) served in a small cup with a teaspoon served as US. During the experiment, the USs were kept in a cooler and out of sight of the participants.

CS. Two children's jewelry boxes served as CSs, and contained the US only in case of a CS+ trial. One box depicted an elephant ('Elmer the Patchwork Elephant'), had coloured squares and yellow linings, and the other depicted fish ('The Rainbow Fish') and was blue. ${ }^{1}$ Which box served as CS+ and CS- was counterbalanced. The $\mathrm{CS}+$ box was also used as CSO (CS+ box but no US) in the partial reinforcement condition and during extinction.

\footnotetext{
1 The characters depicted on the boxes are based on children's books.
}

\section{Design and procedure}

Participants were seen individually between 11 AM and 6 PM. For both studies, testing times were distributed equally across the conditions. Participants gave written consent after arrival in the laboratory, and filled in a hunger VAS. A baseline salivation measurement was then conducted. After that, the participants were shown the jewelry boxes and were informed that they would be repeatedly asked to open them during the experiment. They were then explicitly instructed that one of these boxes sometimes contained something they would eat, whereas the other box would never contain anything. This was done because there is currently a wide consensus that explicit contingency learning is an important component of conditioning (Boddez et al., 2013), and that it might even be necessary for conditioning to occur (Lovibond \& Shanks, 2002). After this, the conditioning procedure started.

Participants were randomly assigned to a continuous reinforcement (CRF) condition or a partial reinforcement (PRF) condition (to be shown later). The instructions given during the experiment were pre-recorded. A trial started when a closed box was placed in front of the participant. After $10 \mathrm{~s}$, desire and US expectancy VAS were filled in. The participant then opened the box, and in case of a CS+ trial, she ate the chocolate mousse that was inside the box. In both the CS+ and CS- trials, she closed the box again, followed by an intertrial interval (ITI) of $10 \mathrm{~s}$, after which the next trial started. The order of the presentation of the trials was random with the restriction that no more than two consecutive trials were of the same trial type ( $\mathrm{CS}+, \mathrm{CS} 0$ or $\mathrm{CS}-)$. Further, two of the same trial types were never spaced apart by more than four other trial types. At baseline, and at the last acquisition, extinction, and reacquisition trials, salivation was measured. Trials were halted during salivation measurements. These measurements were conducted after participants had filled in the desire and expectancy VAS, but before the lids of the boxes were opened. When the cotton roles were removed again, participants took a sip of water to rinse their mouths. The order of the salivation measurements (CS+ or CS- first) at the end of acquisition was counterbalanced. After the acquisition, extinction, and reacquisition phases were completed, participants filled in questionnaires on their idea about the study's hypothesis, CS preference, hunger, BIS-11, RS, liking of the chocolate mousse and time of pre-experimental food intake.

\section{Acquisition, extinction, and reacquisition}

CRF. During acquisition, participants in the CRF condition received six CS+ trials and six CS- trials.

PRF. During acquisition, participants in the PRF condition were given a 50\% reinforcement schedule. Participants received six CS+ trials, six nonreinforced CS0 trials, and six CS- trials. Trial durations were kept similar for the CRF and PRF conditions to achieve similar associative strengths across the conditions (subtract $\mathrm{R}$ method; Bouton \& Sunsay, 2003).

During extinction, participants received 12 CS0 trials. No CS- trials were included after the acquisition phase as an attempt to limit the length of the procedure and to avoid high levels of boredom in participants. After extinction, all participants received four CS+ trials to test for differences in reacquisition.

\section{Statistical analyses and data reduction}

The 12 extinction trials were averaged into four blocks of three trials. Differential acquisition of the desire to eat and US expectancy across conditions were analysed by using a 2 (condition: CRF vs. $\mathrm{PRF}) \times 2$ (CS-type: CS+ vs. CS-) $\times 6$ (acquisition trial) repeatedmeasures ANCOVA, including CS-type (CS) and trial (T) as withinsubjects factors and condition (C) as between-subjects factor. Analyses were performed on US expectancy and desire for chocolate mousse ratings given during $\mathrm{CS}+$ and $\mathrm{CS}-$ trials. Because no 


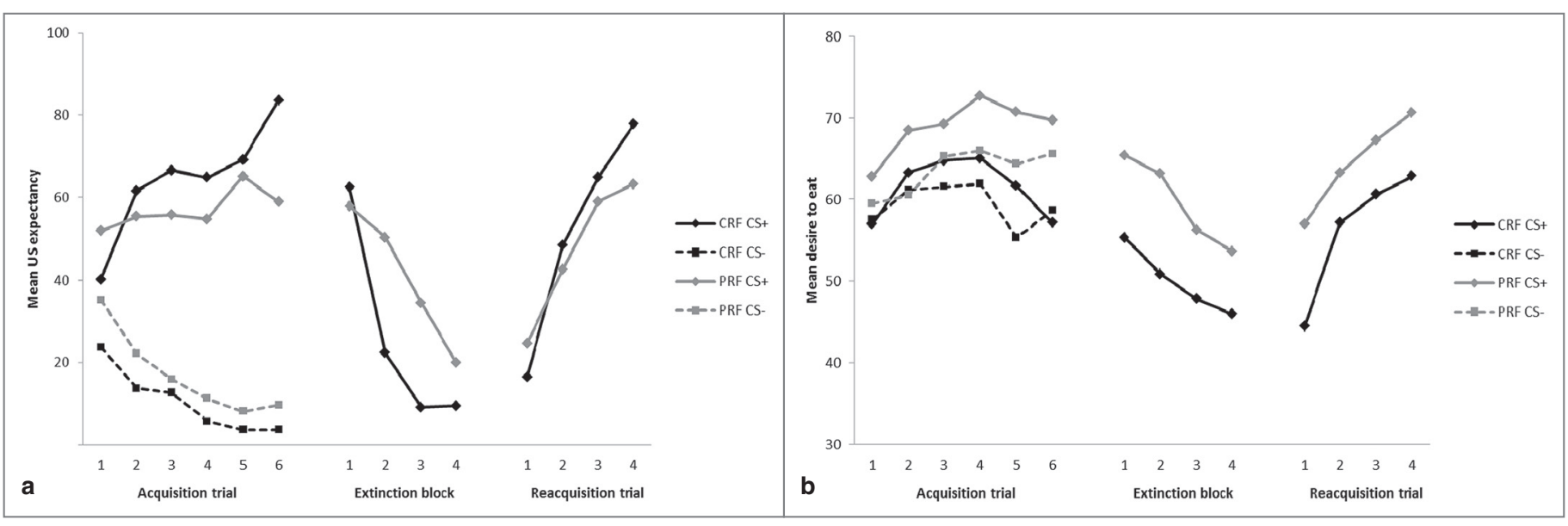

Fig. 1. Mean US expectancy and desire for chocolate mousse, by CS-type, trial, condition, and phase of the experiment (study 1).

CS- trials were included after the acquisition phase, analyses on extinction and reacquisition were performed on CSO (extinction) and $\mathrm{CS}+$ (reacquisition) scores only. Extinction and reacquisition were analysed by separate 2 (condition: CRF vs. PRF) $\times 4$ (extinction block [B] or reacquisition trial) repeated-measures ANCOVAs. The total score of the BIS-11 was centered and included as covariate in the ANCOVAs to assess effects of impulsivity (I) on responses during conditioning, extinction and reacquisition. If necessary, additional analyses were performed to explore significant interactions.

Acquisition of a salivary response was also analysed using repeated-measures ANCOVA, with measurement type (baseline, CS+, CS-) as within-subjects variable, condition as between-subjects factor, and the centered score of the BIS-11 as covariate. Significant interactions were examined using pairwise comparisons. CS preference (CS+ or CS-) was analysed using binomial tests. Chi-square likelihood ratio tests were used to assess differences in CS preference across conditions. Greenhouse-Geisser epsilon corrections are reported for all repeated-measures analyses whenever sphericity was violated. Partial eta squared $\left(\eta_{\mathrm{p}}^{2}\right)$ is reported as a measure of effect size.

Table 1

Participant characteristics per study and across conditions, means with standard deviations in parentheses.

\begin{tabular}{lllll}
\hline & CRF & PRF & $F(1,30)$ & $p$ \\
\hline Study 1 & & & & \\
$n$ & 16 & 16 & & \\
Age & $19.6(1.7)$ & $19.4(1.0)$ & 0.06 & .80 \\
BMI & $22.9(5.2)$ & $21.4(2.7)$ & 1.05 & .32 \\
Baseline hunger & $42.6(20.3)$ & $51.6(22.5)$ & 1.41 & .24 \\
Post hunger & $42.2(21.0)$ & $51.9(21.1)$ & 1.69 & .20 \\
BIS-11 total & $58.8(9.8)$ & $58.1(7.1)$ & 0.06 & .54 \\
RS & $12.5(4.9)$ & $10.9(4.2)$ & 1.03 & .81 \\
Chocolate mousse liking & $77.4(14.2)$ & $80.2(10.6)$ & 0.39 & .32 \\
Study 2 & & & & \\
$n$ & 24 & 24 & & \\
Age & $20.1(1.9)$ & $20.1(1.6)$ & 0.00 & $>.99$ \\
BMI & $22.7(3.7)$ & $22.8(2.8)$ & 0.02 & .90 \\
Baseline hunger & $48.1(21.8)$ & $52.8(17.9)$ & 0.67 & .42 \\
Post hunger & $45.7(31.2)$ & $41.5(19.4)$ & 0.31 & .58 \\
BIS-11 total & $58.0(11.2)$ & $58.5(11.7)$ & 0.02 & .88 \\
RS & $12.2(5.5)$ & $14.1(5.4)$ & 1.49 & .23 \\
Chocolate mousse liking & $77.8(20.1)$ & $79.4(14.7)$ & 0.09 & .76 \\
\hline
\end{tabular}

Results

\section{Participant characteristics}

No significant differences across conditions were found for age, BMI, hunger, BIS-11, RS, and liking of chocolate mousse (see Table 1, Study 1).

\section{US expectancy}

A differential acquisition of US expectancies (i.e., US expectancy is higher over time in response to the CS+ vs. CS-) was present, as indicated by a significant $\mathrm{CS} \times \mathrm{T}$ interaction, $F(3.85,107.80)=18.79$, $p<.001, \eta_{\mathrm{p}}^{2}=.40$, with no significant differences across conditions $(\mathrm{CS} \times \mathrm{T} \times \mathrm{C}), F(3.85,107.80)=1.45, p=.22, \eta_{\mathrm{p}}^{2}=.05$ (see Fig. 1a). On trial 6 a significant differentiation was present, $F(1,28)=135.93$, $p<.001, \eta_{\mathrm{p}}^{2}=.83$; differential expectancy was larger in the CRF condition than the PRF condition $(\mathrm{CS} \times \mathrm{C}), F(1,28)=7.18, p=.012, \eta_{\mathrm{p}}^{2}=.20$, and larger (though only marginally significant) in higher impulsives vs. lower impulsives $(\mathrm{CS} \times \mathrm{I}), F(1,28)=3.50, p=.07, \eta_{\mathrm{p}}^{2}=.11$. Impulsivity influenced conditioned responses over time, as evidenced by a significant $\mathrm{CS} \times \mathrm{T} \times \mathrm{I}$ interaction, $F(3.85,107.80)=2.85, p=.029$, $\eta_{\mathrm{p}}^{2}=.09$. Condition had a significant effect on this interaction, as evidenced by a CS $\times \mathrm{T} \times \mathrm{C} \times \mathrm{I}$ interaction, $F(3.85,107.80)=2.54, p=.046$, $\eta_{\mathrm{p}}^{2}=.08$. Follow-up tests showed that impulsivity did not affect responses within the CRF condition, $F<1$, but did within the PRF condition $(\mathrm{CS} \times \mathrm{T} \times \mathrm{I}), F(5,70)=3.85, p=.004, \eta_{\mathrm{p}}^{2}=.22$. These results suggest impulsivity to be related to larger US expectancies specifically within the PRF condition (see Fig. 2). ${ }^{2}$

From the last acquisition trial to the first extinction block, the decrease in US expectancy in response to the CS+ was already larger for the CRF (vs. PRF) condition $(\mathrm{T} \times \mathrm{C}), F(1,28)=5.22, p=.03, \eta_{\mathrm{p}}^{2}=.16$. There was an overall decrease in US expectancies throughout extinction, $F(2.38,66.67)=116.25, p<.001, \eta_{\mathrm{p}}^{2}=.81$, and as expected, this decrease was more pronounced for the CRF condition $(\mathrm{T} \times \mathrm{C})$, $F(2.38,66.67)=16.51, p<.001, \eta_{\mathrm{p}}^{2}=.37$ (see Fig. $1 \mathrm{a}$ ). Using a Bonferroni-corrected alpha of .0125 , pairwise comparisons suggested a facilitated extinction in the CRF condition: a smaller nondifferential US expectancy was found in the CRF condition vs. the PRF condition for block $2(p<.001)$ and block $3, p<.001$ (block $1: p=.28$; block $4: p=.03$ ). While impulsivity did not moderate ex-

\footnotetext{
2 The differentiation on trial 1 did not differ significantly across conditions or levels of impulsivity, $F \mathrm{~s}<1$, nor by their interaction, $F(1,28)=1.52, p=.23, \eta_{\mathrm{p}}^{2}=.05$.
} 


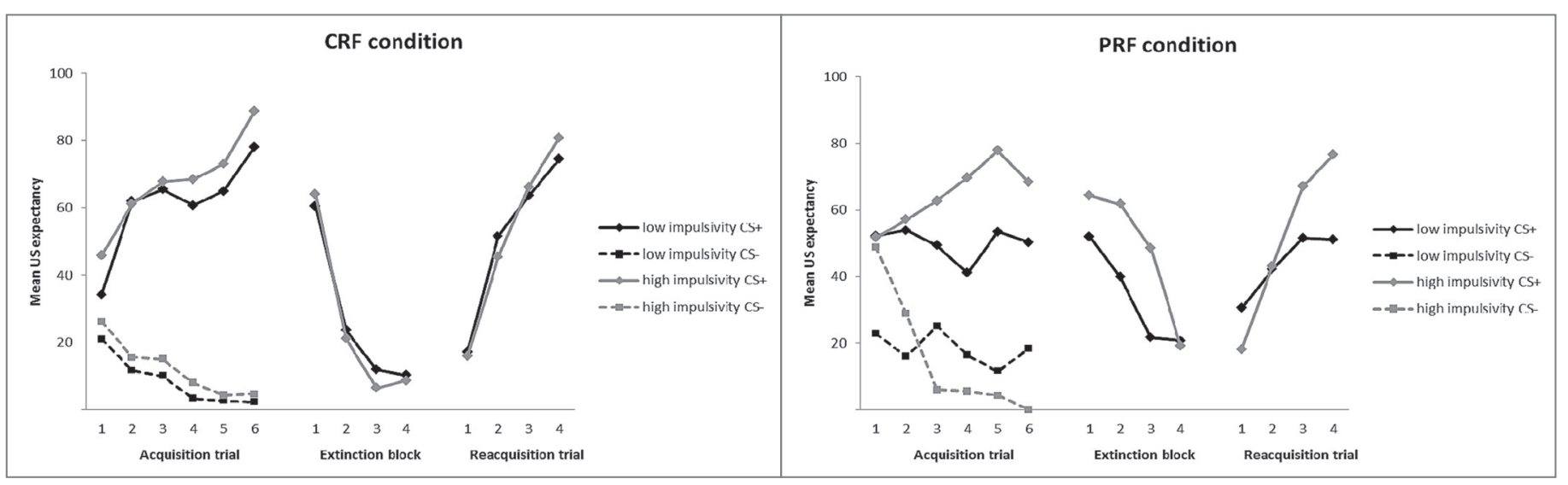

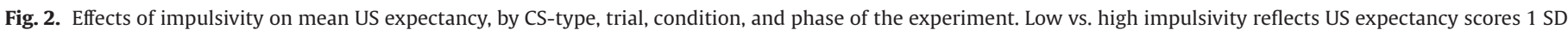
below vs. above the mean of the BIS-11 (study 1 ).

tinction scores overall $(\mathrm{T} \times \mathrm{I}), F(2.38,66.67)=1.97, p=.14, \eta_{\mathrm{p}}^{2}=.07$, the $\mathrm{T} \times \mathrm{C} \times \mathrm{I}$ interaction was significant, $F(2.38,66.67)=2.45, p=.032$, $\eta_{\mathrm{p}}^{2}=.11$. Follow-up analyses revealed no effects of impulsivity on extinction within the CRF condition $(\mathrm{T} \times \mathrm{I}), F<1$, while impulsivity was associated with differential extinction patterns within the PRF condition, $F(3,42)=2.55, p=.028, \eta_{\mathrm{p}}^{2}=.21$ : within this condition, the more impulsive participants showed slower extinction (see Fig. 2).

On the first reacquisition trial, there was no significant difference between the conditions in US expectancy, $F<1$. Reacquisition of US expectancies was present, $F(1.97,55.07)=61.19, p<.001$, $\eta_{\mathrm{p}}^{2}=.69$, with a non-significant trend that is in line with our hypotheses suggesting a more rapid reacquisition in the CRF condition than in the PRF condition $(\mathrm{T} \times \mathrm{C}), F(1.97,55.07)=2.52, p=.09$, $\eta_{\mathrm{p}}^{2}=.08$ (see Fig. 1a). The $\mathrm{T} \times \mathrm{I}$ interaction was marginally significant, $F(1.97,55.07)=2.98, p=.06, \eta_{\mathrm{p}}^{2}=.10$, suggesting a moderating role of impulsivity in reacquisition: impulsivity was related to a more rapid reacquisition (see Fig. 2). This interaction was independent of condition $(\mathrm{T} \times \mathrm{C} \times \mathrm{I}), F(1.97,55.07)=1.14, p=.33, \eta_{\mathrm{p}}^{2}=.04$. In line with this, both participants in the CRF condition and those with higher impulsivity showed significantly greater reacquisition scores on the last reacquisition trial, $F(1,28)=4.20, p=.050, \eta_{\mathrm{p}}^{2}=.13$, $F(1,28)=4.84, p=.036, \eta_{\mathrm{p}}^{2}=.15$. Thus, participants who received CRF and those who were more impulsive showed evidence of a more rapid reacquisition of US expectancies.

\section{Desire to eat}

Acquisition of differential desire for chocolate mousse was not significant $(\mathrm{CS} \times \mathrm{T})$, with no differences between conditions $(\mathrm{CS} \times \mathrm{T} \times \mathrm{C}), F \mathrm{~s}<1.04$, or across levels of impulsivity $(\mathrm{CS} \times \mathrm{T} \times \mathrm{I}), F(3.30$, $92.49)=1.69, p=.17, \eta_{\mathrm{p}}^{2}=.06$. Thus, no evidence was found indicating a robust acquisition of the desire for chocolate mousse. Since a conditioned desire to eat cannot be extinguished if not first acquired, no statistical tests on extinction and reacquisition performance were conducted (see Fig. 1b).

\section{Salivation}

One participant was excluded from salivation analyses because she scored $>3$ SD above the mean on at least one of the measures used to assess acquisition (baseline, $\mathrm{CS}_{+}, \mathrm{CS}-$ ). A main effect of time point was found (baseline vs. CS+ vs. CS-) $F(2,54)=4.86, p=.011$, $\eta_{\mathrm{p}}^{2}=.15$ : Bonferroni-corrected pairwise comparisons showed a significant increase from baseline to $\mathrm{CS}+(p=.032)$, while both the increase from baseline to CS- $(p=.26)$, and the difference between $\mathrm{CS}+$ and CS- $(p=.33)$ were not. Interactions with condition and impulsivity were non-significant, as was the three-way interaction, $F S<1$. The increase in responding to the CS+ but not CS- could be regarded as tentative evidence for a conditioned salivation effect. However, strong evidence for acquisition of conditioned salivary responses would have taken the form of significantly higher salivation to CS+ than CS-. Because this was not found, statistical tests on extinction and reacquisition of salivary response were not conducted (see Table 2).

\section{CS liking}

CS liking data of three participants were missing. At the end of the procedure, the CS+ was preferred above the CS- by $90 \%$ of the participants $(n=26)$, binomial test, $p<.001$. Thus, participants showed evidence of conditioned positive evaluations of the CS+. Condition did not affect CS preference, $\chi^{2}(1)=0.31, p=.58$ (CS+ choice: CRF: 13 or $86.7 \%$; PRF: 13 or $92.6 \%$ ).

\section{Discussion}

The US expectancy data were in line with the hypotheses. Participants receiving continuous or partial reinforcement learned to expect to eat chocolate mousse in the presence of a stimulus predicting the US. When the CS+ was no longer followed by the US during extinction, participants who received partial reinforcement were slower to extinguish their expectancies, compared with participants in the CRF condition. This reflects a PREE. Furthermore, participants in the CRF vs. PRF condition showed a more rapid reacquisition. However, these effects may have been caused by differences in acquisition levels or by nonassociative processes (e.g., differences in arousal).

Impulsivity had an effect on the acquisition, extinction, and reacquisition of US expectancies. More impulsive individuals showed a larger differential acquisition of expectancies in specifically the PRF condition, a more pronounced PREE, and a generally more rapid reacquisition of expectancies. Again, nonassociative processes as well

Table 2

Salivation in grams, by CS-type and condition at the end of the different phases of the experiment, means with standard deviations in parentheses (study 1).

\begin{tabular}{lll}
\hline & CRF condition $(n=15)$ & PRF condition $(n=16)$ \\
\hline Baseline & $0.37(0.26)$ & $0.27(0.11)$ \\
Acquisition & & \\
CS+ & $0.57(0.35)$ & $0.37(0.18)$ \\
CS- & $0.46(0.27)$ & $0.35(0.21)$ \\
Extinction & $0.44(0.29)$ & $0.29(0.22)$ \\
Reacquisition & $0.58(0.33)$ & $0.31(0.16)$ \\
\hline
\end{tabular}




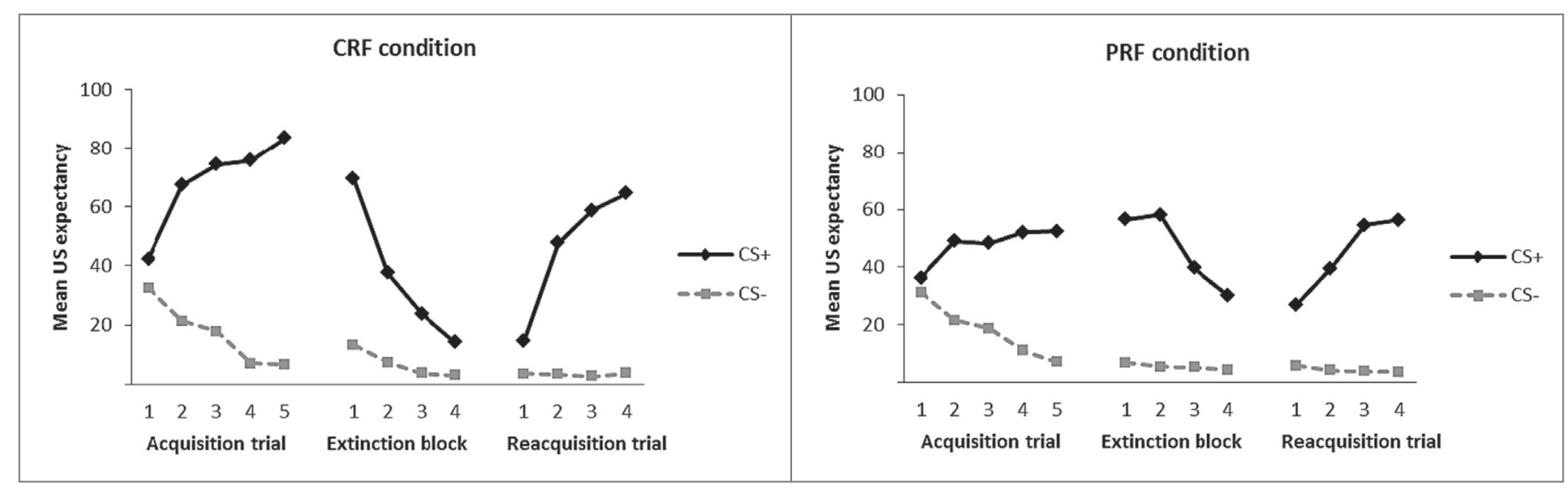

Fig. 3. Mean US expectancy, by CS-type, trial, condition, and phase of the experiment (study 2).

as differences in acquisition levels could be responsible for the patterns observed during extinction and reacquisition.

Conditioned positive evaluations of the CS+ were found, although this might be explained by an increased number of exposures to the CS+ vs. the CS- box. Further, no conditioned salivary response was found. Similarly, no reliable acquisition of conditioned desires was detected, which is in contrast to studies that used relatively similar conditioning procedures (e.g., Van Gucht et al., 2008). Before drawing any preliminary conclusions, the experiment was repeated with some adaptations to the design, including the use of a stronger, more salient US and larger sample size.

\section{Study 2}

\section{Introduction}

The findings of study 1 were generally in favor of our hypotheses; however, the study's design could benefit from some improvements. Therefore, a second study was conducted, including the following changes: first, the number of acquisition trials was reduced to 5; second, the US size was slightly increased to facilitate conditioning (Morris \& Bouton, 2006); third, the desire question (VAS) was slightly altered to better direct the participants' attention towards the presented CS; fourth, CS- trials were included throughout all phases of the experiment to control for nonassociative processes. Because previous appetitive food conditioning studies in humans have generally not achieved successful extinction of the desire for food, a pilot study including these changes to the design was conducted first. The pilot data (unpublished) showed extinction to be complete within 12 trials following continuous reinforcement.

\section{Methods and materials}

\section{Participants}

Forty-eight participants took part in this study. One participant was excluded from the study sample because she had a BMI of 15 and was considered substantially underweight. She was replaced by another participant to ensure complete counterbalancing.

\section{Measurements and stimuli}

All measurements and stimuli were identical to those used in study 1 except for a few minor changes. The question stated on the desire-VAS was changed to 'When presented this box, how strong is your desire for chocolate mousse right now' (Van Gucht, Baeyens,
Vansteenwegen, Hermans, \& Beckers, 2010). Furthermore, the US size was increased from $\sim 2 \mathrm{~g}$ to $\sim 3.5 \mathrm{~g}$ (i.e., one heaped teaspoon).

\section{Design and procedure}

The design of study 2 was largely similar to the design used in study 1 except for the changes as discussed earlier. The order of salivation measurements (CS+ or CS- first) was counterbalanced across phases of the experiment. The order of the expectancy and desire VAS and which box served as CS+ or CS- was randomised across participants.

\section{Statistical analyses and missing data}

Data analyses were identical to analyses in study 1, except for the analyses of extinction and reacquisition data since CS- trials were now included in these conditioning phases. Differential extinction and reacquisition of the desire to eat and US expectancies were analysed by using 2 (condition: CRF vs. PRF) $\times 2$ (CS-type: CS+ vs. CS-) $\times 5$ resp. 4 resp. 4 (acquisition trial resp. extinction block resp. reacquisition trial) repeated-measures ANCOVAs, including CStype and trial/block as within-subjects factors, condition as betweensubjects factor, and the centered score of the BIS-11 as covariate.

For one participant, data were missing for one desire-VAS during reacquisition. The value of this score was estimated using the multiple imputation (MI) method (Schafer \& Graham, 2002).

Results

Participant characteristics

No significant differences across conditions were found for age, BMI, hunger, BIS-11, RS, and liking of chocolate mousse (see Table 1, Study 2).

\section{US expectancy}

Differential acquisition of US expectancy was present, as evidenced by a significant $\mathrm{CS} \times \mathrm{T}$ interaction, $F(3.13,137.72)=33.81$, $p<.001, \eta_{\mathrm{p}}^{2}=.44$, with a non-significant trend towards a larger differentiation in the $\mathrm{CRF}$ condition $(\mathrm{CS} \times \mathrm{T} \times \mathrm{C}), F(3.13,137.72)=2.16$, $p=.09, \eta_{\mathrm{p}}^{2}=.05$ (see Fig. 3 ). This resulted in a significant differentiation on trial $5, F(1,44)=365.96, p<.001, \eta_{\mathrm{p}}^{2}=.89$, this differentiation being larger in the CRF condition than in the PRF condition, $F(1,44)=23.89, p<.001, \eta_{\mathrm{p}}^{2}=.35$. Impulsivity did not have an effect on this differentiation, $F(1,44)=1.47, p=.23, \eta_{\mathrm{p}}^{2}=.03$, and did not moderate conditioned responses over time, neither overall $(\mathrm{CS} \times \mathrm{T} \times \mathrm{I})$, $F<1$, nor by condition $(\mathrm{CS} \times \mathrm{T} \times \mathrm{C} \times \mathrm{I}), F(3.13,44)=2.03, p=.11$, $\eta_{\mathrm{p}}^{2}=.04$. 


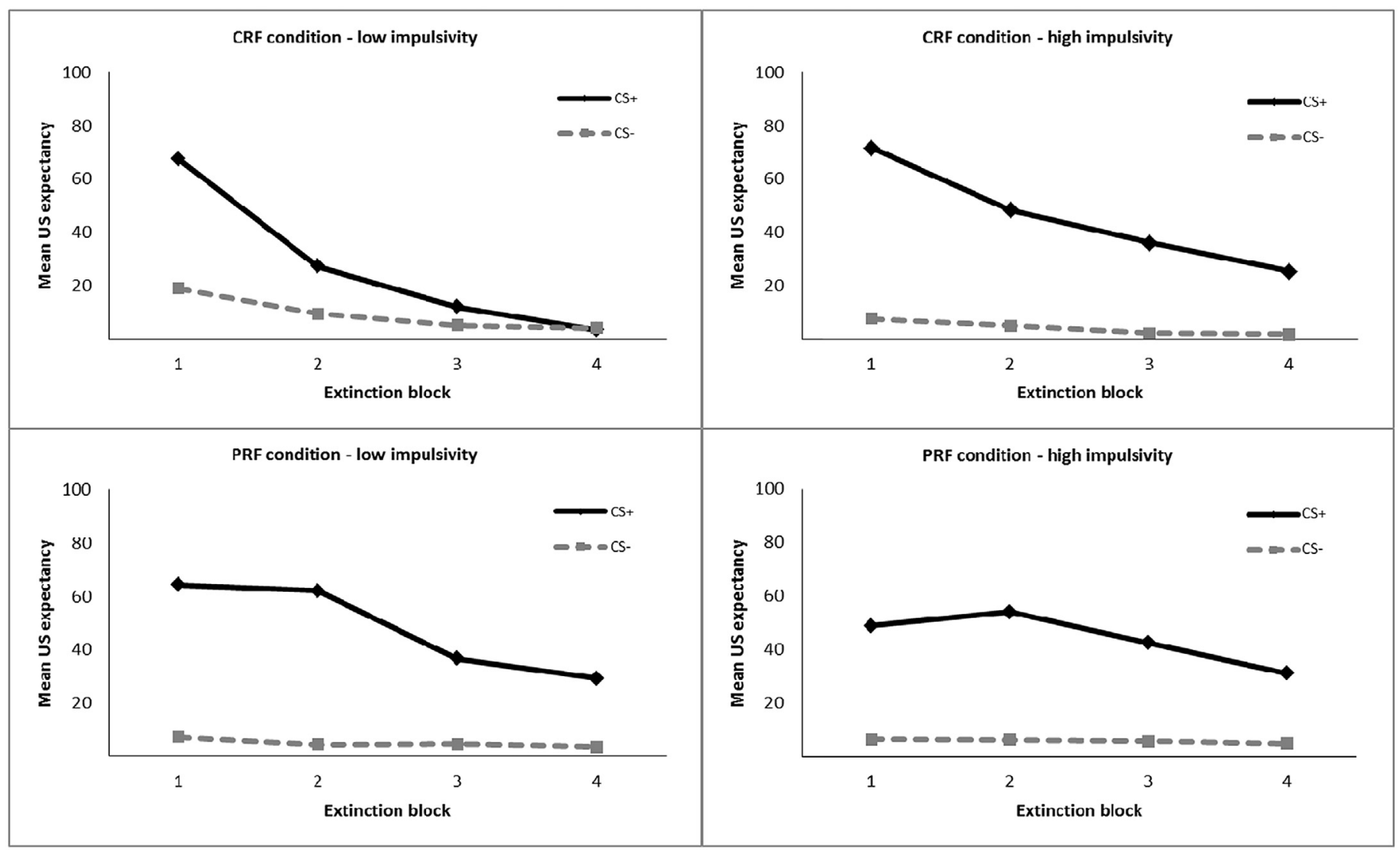

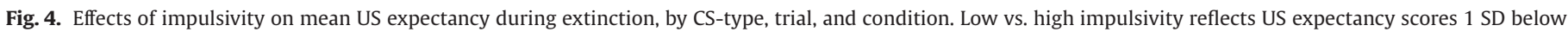
vs. above the mean of the BIS-11 (study 2).

From the last acquisition trial to the first extinction block, the CRF already showed a greater change in differential US expectancies, $F(1,44)=18.84, p<.001, \eta_{\mathrm{p}}^{2}=.30$. Differential US expectancy decreased significantly during extinction $(\mathrm{CS} \times \mathrm{B}), F(2.15,94.77)=70.55$, $p<.001, \eta_{\mathrm{p}}^{2}=.62$, with significant differences across conditions $(\mathrm{CS} \times \mathrm{B} \times \mathrm{C}), F(2.15,94.77)=11.57, p<.001, \eta_{\mathrm{p}}^{2}=.21$ (see Fig. 3). Followup analyses per condition and using a Bonferroni-corrected alpha of .017 indicated better extinction performance in the CRF condition compared with the PRF condition. While participants in the CRF condition already showed clear extinction during the second extinction block, $F(1,22)=50.12, p<.001, \eta_{\mathrm{p}}^{2}=.70$, participants in the PRF condition did not show evidence for a decrease in expectancies until block 3 (compared with the first extinction block), $F(1$, $22)=18.51, p<.001, \eta_{\mathrm{p}}^{2}=.46$ (block $2: F<1$ ). Additionally, the difference between CS+ and CS- expectancy scores was still higher in the PRF condition than in the CRF condition during block 4, $F(1$, $44)=7.48, p=.009, \eta_{\mathrm{p}}^{2}=.15$. Thus, these results indicate both a slower and less complete extinction in the PRF condition, compared with the CRF condition, clearly reflecting a PREE.

Impulsivity appeared to moderate overall extinction scores $(\mathrm{CS} \times \mathrm{B} \times \mathrm{I}), F(2.15,94.77)=3.33, p=.037, \eta_{\mathrm{p}}^{2}=.07$, independent of condition ( $\mathrm{CS} \times \mathrm{B} \times \mathrm{C} \times \mathrm{I}), F<1$ (see Fig. 4). Follow-up analyses per block $(\mathrm{CS} \times \mathrm{B})$ and using a Bonferroni-corrected alpha of .0125 suggest a slower extinction of US expectancies during the second half of extinction for participants who are more impulsive (block 1: $p=.95$; block 2: $p=.21$; block 3: $p=.009$; block 4: $p=.009$ ). Thus, higher impulsivity is related to overall worse extinction performance. Since BMI has been related to deficits in working memory which might be associated with learning (extinction) deficits (Lasselin et al., 2013; Maayan, Hoogendoorn, Sweat, \& Convit, 2011), the correlation between the BIS-11 and BMI was calculated $(r=.24 ; p=.1)$, and BMI was added to the model. BMI did not interact with differential extinction, $F<1$, nor did it result in a very different $\mathrm{CS} \times \mathrm{B} \times \mathrm{I}$ interaction, $F(2.12,88.99)=2.59, p=.078, \eta_{p}^{2}=.06$. Thus, it seems that the slower extinction by participants with higher impulsivity was not explained by their higher BMI.

A significant CS+ vs. CS- differentiation was still present on the first reacquisition trial, $F(1,44)=24.16, p<.001, \eta_{\mathrm{p}}^{2}=.35$, with no differences across conditions, $F(1,44)=2.10, p=.15, \eta_{\mathrm{p}}^{2}=.05$ (see Fig. 3). Reacquisition of expectancies was significant $(\mathrm{CS} \times \mathrm{T}), F(2.25$, $99.18)=49.80, p<.001, \eta_{\mathrm{p}}^{2}=.53$. For the CRF condition evidence was found for a more rapid reacquisition compared with the PRF condition $(\mathrm{CS} \times \mathrm{T} \times \mathrm{C}), F(2.25,99.18)=2.76, p=.06, \eta_{\mathrm{p}}^{2}=.06$. Impulsivity did not moderate speed of reacquisition; neither overall $(\mathrm{CS} \times \mathrm{T} \times \mathrm{I}), F(2.25,99.18)=1.74, p=.18, \eta_{\mathrm{p}}^{2}=.04$ nor by condition $(\mathrm{CS} \times \mathrm{T} \times \mathrm{C} \times \mathrm{I}), F(2.25,99.18)=1.54, p=.22, \eta_{\mathrm{p}}^{2}=.03$.

\section{Desire to eat}

Differential acquisition of the desire for chocolate mousse was present, as shown by a significant $\mathrm{CS} \times \mathrm{T}$ interaction, $F(2.95$, $129.85)=5.04, p=.003, \eta_{\mathrm{p}}^{2}=.10$, with no significant differences across conditions ( $\mathrm{CS} \times \mathrm{T} \times \mathrm{C}$ ), $F<1$ (see Fig. 5). Impulsivity did not moderate these interactions $(\mathrm{CS} \times \mathrm{T} \times \mathrm{I}$; $\mathrm{CS} \times \mathrm{T} \times \mathrm{C} \times \mathrm{I}), F \mathrm{~s}<1$. The differentiation resulted in a significantly higher desire in response to the $\mathrm{CS}+$ compared to the CS- on trial $5, F(1,44)=10.65, p=.002, \eta_{\mathrm{p}}^{2}=.20$, with no differences across conditions, $F<1$.

A differentiation was still present on block $1, F(1,44)=40.37$, $p<.001, \eta_{\mathrm{p}}^{2}=.48$, with no differences across conditions, $F<1$. A significant overall extinction of conditioned desires was found $(\mathrm{CS} \times \mathrm{B})$, $F(2.41,106.12)=3.89, p=.017, \eta_{\mathrm{p}}^{2}=.08$, as well as a significant $\mathrm{CS} \times \mathrm{B} \times \mathrm{C}$ interaction, $F(2.41,106.12)=3.86, p=.018, \eta_{\mathrm{p}}^{2}=.08$. 


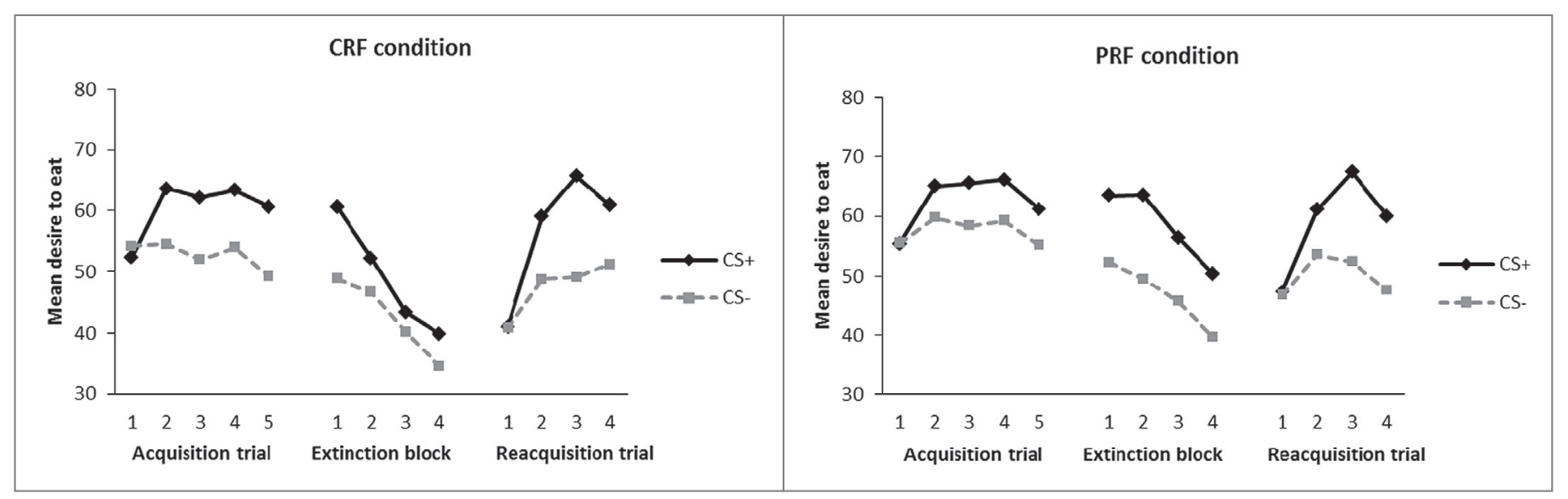

Fig. 5. Mean desire for chocolate mousse, by CS-type, trial, condition, and phase of the experiment (study 2).

Follow-up analyses indicated a significant $\mathrm{CS} \times \mathrm{T}$ interaction within the CRF condition, $F(3,66)=7.04, p<.001, \eta_{\mathrm{p}}^{2}=.24$, while no such interaction was found for the PRF condition, $F(2.05,45.04)=1.19$, $p=.31, \eta_{\mathrm{p}}^{2}=.05$, indicating an extinction of desire within the CRF condition but not in the PRF condition (see Fig. 5). On the last extinction block, a differentiation is present, $F(1,44)=21.39, p<.001$, $\eta_{\mathrm{p}}^{2}=.33$, that is not significantly different for the two conditions, $F(1,44)=2.42, p=.13, \eta_{\mathrm{p}}^{2}=.05$. Thus, overall, these findings point towards a PREE; conditioned desires are resistant to extinction after partial reinforcement but less so after continuous reinforcement.
Impulsivity did not influence extinction overall $(\mathrm{CS} \times \mathrm{T} \times \mathrm{I})$, nor by condition, $(\mathrm{CS} \times \mathrm{T} \times \mathrm{C} \times \mathrm{I})$, Fs $<1$.

On the first reacquisition trial, no significant differentiation was present, with no differences across conditions, $F s<1$. Reacquisition of desire ratings was significant $(\mathrm{CS} \times \mathrm{T}), F(3,132)=11.97, p<.001$, $\eta_{\mathrm{p}}^{2}=.21$, with no differences across conditions $(\mathrm{CS} \times \mathrm{T} \times \mathrm{C}), F<1$ (see Fig. 5). Impulsivity showed a marginally significant interaction with reacquisition over time $(\mathrm{CS} \times \mathrm{T} \times \mathrm{I}), F(3,132)=2.46, p=.066$, $\eta_{\mathrm{p}}^{2}=.05$, independent of condition $(\mathrm{CS} \times \mathrm{T} \times \mathrm{C} \times \mathrm{I}), F(3,132)=1.02$, $p=.39, \eta_{\mathrm{p}}^{2}=.02$ (see Fig. 6 ). Further analyses showed that differen-

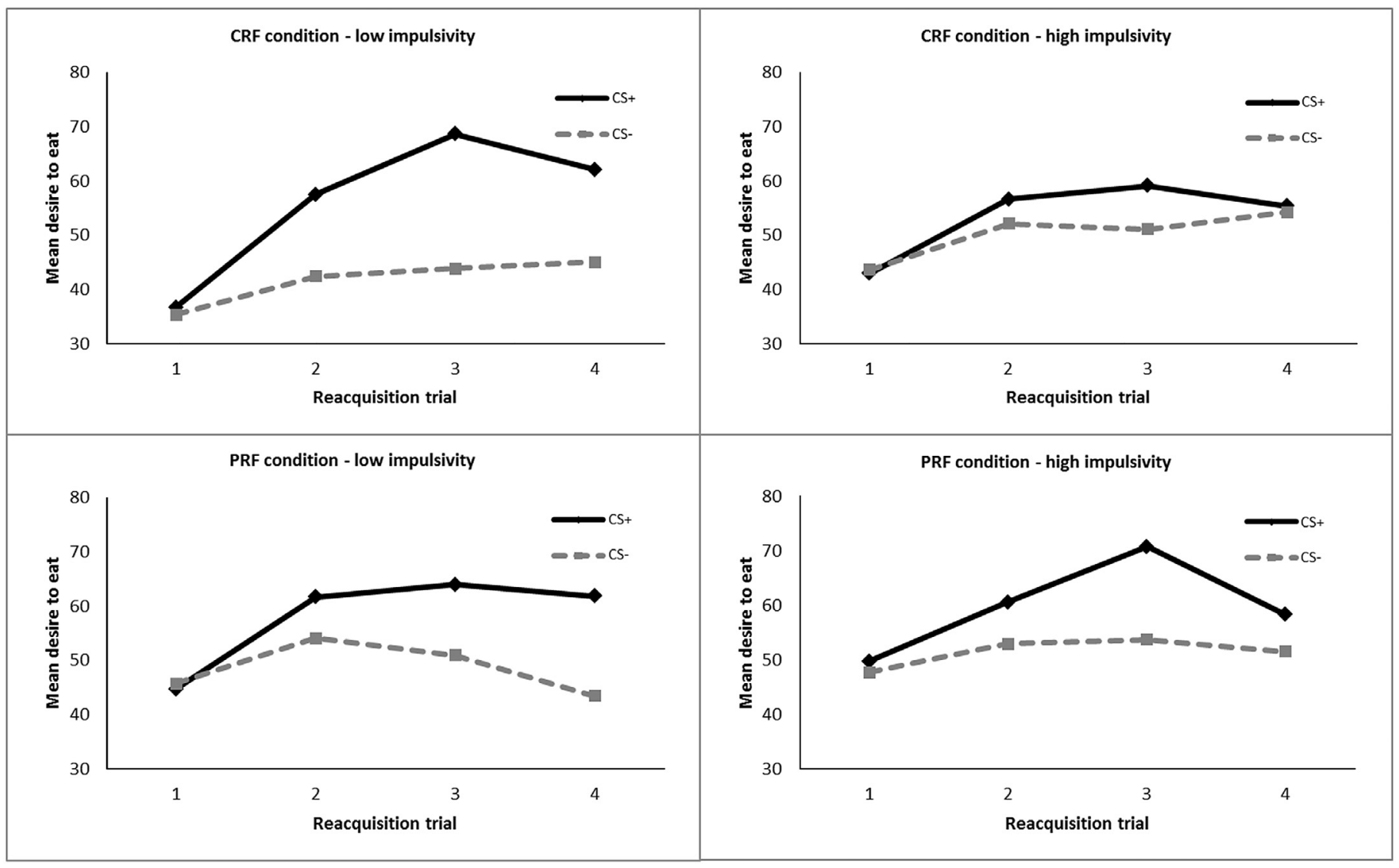

Fig. 6. Effects of impulsivity on mean desire for chocolate mousse during reacquisition, by CS-type, trial and condition. Low vs. high impulsivity reflects desire scores 1 SD below vs. above the mean of the BIS-11 (study 2). 
Table 3

Salivation in grams, by CS-type and condition at the end of the different phases of the experiment, means with standard deviations in parentheses (study 2).

\begin{tabular}{lll}
\hline & CRF condition $(n=23)$ & PRF condition $(n=23)$ \\
\hline $\begin{array}{l}\text { Baseline } \\
\text { Acquisition }\end{array}$ & $0.33(0.19)$ & $0.32(0.18)$ \\
$\quad$ CS+ & $0.41(0.29)$ & $0.39(0.21)$ \\
$\quad$ CS- & $0.40(0.22)$ & $0.35(0.23)$ \\
Extinction & & \\
CS+ & $0.30(0.26)$ & $0.25(0.15)$ \\
CS- & $0.28(0.17)$ & $0.26(0.17)$ \\
Reacquisition & & \\
CS+ & $0.36(0.24)$ & $0.32(0.22)$ \\
CS- & $0.36(0.19)$ & $0.35(0.24)$ \\
\hline
\end{tabular}

tial desire on the last reacquisition trial was smaller in high impulsive vs. low impulsive participants, $F(1,44)=6.19, p=.017, \eta_{\mathrm{p}}^{2}=.12$, suggesting that impulsivity hindered the reacquisition of conditioned desires.

\section{Salivation}

Two participants were excluded from analyses because they scored $>3$ SD above the mean on at least one of the measures used to assess acquisition. Analysis of salivation during baseline, $\mathrm{CS}+$ and CS- exposures revealed a significant main effect, $F(2,84)=4.17$, $p=.019, \eta_{\mathrm{p}}^{2}=.09$. Bonferroni-corrected pairwise comparisons suggested an increase in salivation from baseline to $\mathrm{CS}+(p=.034)$ but not from baseline to CS $-(p=.18)$, and there were no differences between CS+ and CS- salivation $(p>.99)$. Once again, the increase in salivation to CS+ but not CS- from baseline might provide weak evidence of conditioned salivation. Condition did not moderate the overall interaction, $F<1$, nor did impulsivity, $F(2,84)=2.41, p=.1$, $\eta_{\mathrm{p}}^{2}=.05$. Because the difference in salivation between CS+ and CSdid not reach significance, analyses on extinction and reacquisition were not performed (see Table 3 ).

\section{CS liking}

The CS+ was preferred over the CS- by 37 participants (77\%), binomial test, $p<.001$. There was a trend towards participants in the CRF condition choosing the CS+ more often, $\chi^{2}(1)=3.04, p=.08$ (CRF: 21 participants or $88 \%$; PRF: 16 participants or $67 \%$ ).

\section{Discussion}

In this second study, a successful acquisition of a conditioned desire for chocolate mousse was demonstrated. Importantly, some of the main findings of study 1 were replicated and extended by demonstrating a partial reinforcement extinction effect that was reflected in both US expectancies and the desire for food, and which could not be explained by differences in arousal across conditions. Similar to study 1 , a more rapid reacquisition of US expectancies after continuous vs. partial reinforcement was demonstrated. Further, impulsivity again appeared to be related to worse extinction performance with regard to US expectancies, although in the present study this effect was not specific to the PRF condition. Only in study 2 , impulsivity was related to a less complete recovery of conditioned desires for chocolate mousse when CSs were again reinforced after extinction. Finally, a preference for the CS+ over the CSwas again clearly demonstrated in the forced-choice task.

\section{General discussion}

One aim of the two studies reported here was to examine whether partial reinforcement of food cues would result in a partial reinforcement extinction effect (PREE) in humans and whether it would slow down a return of conditioned responses when the CS-US contingency is again reinforced after extinction. A further aim was to assess whether impulsivity moderated conditioned appetitive responses during each conditioning phase. As argued in the Introduction, effects of partial reinforcement schedules and an impulsive personality on appetitive responses during different phases of conditioning may help us to understand inter-individual differences in dieting success.

The acquisition of US expectancies was successful in both studies. In the second study, an acquisition of conditioned desires for chocolate mousse was also demonstrated; after repeated pairings of an initially neutral stimulus (a specific box) with the intake of food, participants reported a greater desire for this food when exposed to the intake-associated box (CS+) compared with a control box (CS-). This replicates findings of previous appetitive conditioning studies. Extinction of conditioned responses to food cues was slowed down by a partial reinforcement schedule, and some evidence was found for a slower extinction with higher levels of impulsivity. Reacquisition of US expectancies was reduced after acquisition with partial reinforcement. Finally, a conditioned preference for the CS+ was found, as well as weak evidence for a conditioned salivary response: across the studies, salivation in response to the CS+ was significantly higher than baseline, whereas this difference was non-significant for the CS- (see also van den Akker et al., 2013). Closer inspection of the salivation patterns suggest that strong carryover effects (i.e., measuring CS+ or CS- salivation first) may have contributed to the lack of a clear difference between CS+ and CS-. Additionally, effects on salivation seem to be very small and the current studies might not have had sufficient power to detect such small effects.

Partial reinforcement in humans has previously only been investigated outside the food domain (e.g., Abad, Ramos-Álvarez, \& Rosas, 2009; Pittenger \& Pavlik, 1988). A new and interesting finding is that continuous and partial reinforcement schedules had differential effects on extinction after appetitive conditioning to food rewards. First, participants in the CRF vs. PRF condition showed a better extinction of US expectancies. This extinction was more rapid and more complete. Second, extinction of the conditioned desire for chocolate mousse showed a comparable pattern: after partial reinforcement extinction was not reached while continuous reinforcement did lead to extinction, though the differentiation between the $\mathrm{CS}+$ and $\mathrm{CS}$ - in the latter group seemed to have returned towards the end of the extinction phase. These findings demonstrate partial reinforcement extinction effects in the food domain in humans and are in line with findings of studies conducted in animals (e.g., Haselgrove et al., 2004). It may be noted that the present conditioning procedure was not exclusively Pavlovian. Although provision of the US was not within the participant's control (in line with Pavlovian learning principles), the procedure still involved instrumental learning components: participants had to open a box to obtain the food US. However, the PREE has also been reported for instrumental procedures (Mackintosh, 1974). Further, instrumental learning is thought to involve Pavlovian conditioning of cues that are embedded in the task (Bouton, 2007), and these would elicit Pavlovian CRs as measured by the current outcome measures. Therefore, a possible influence of instrumental learning does not seem to be a problem for the general perspective. The present results also provide some insight into the relationship between US expectancies and conditioned desires during extinction: the resulting heightened US expectancies in the PRF condition went hand in hand with a clear resistance to extinction of conditioned desires, whereas the better extinction of expectancies in the CRF condition occurred in parallel with a better extinction of conditioned desires. This suggests that extinction of US expectancies and desires could be more narrowly related than has previously been suggested (Van Gucht et al., 2010).

Another new finding is that impulsivity predicted a worse extinction of expectations to receive a food US, the strongest evi- 
dence for this being found in study 2 . A worse extinction of reward expectancies in higher (rash) impulsive individuals might be explained by learning deficits caused by a relatively poor functioning OFC (see Introduction). Previous experiments reporting comparable extinction deficits in humans are scarce. A few studies reported a decreased ability to modulate response behaviour during extinction and reversal learning (e.g., when a CS is first associated with reward and then with punishment) in healthy impulsive participants (Avila \& Parcet, 2000; Franken, van Strien, Nijs, \& Muris, 2008; Gullo, Jackson, \& Dawe, 2010; but see Papachristou et al., 2013). However, since the findings of the two studies reported here were somewhat inconsistent, we suggest future studies have yet to determine whether rash impulsiveness is indeed related to extinction deficits.

Besides the effects of partial reinforcement procedures and impulsivity on extinction, these variables also appeared to influence reacquisition performance. In line with our hypothesis, participants in the PRF vs. CRF condition showed a less rapid return of US expectancies. As argued in the Introduction, a slower reacquisition may be the result of previously partially reinforced cues not predicting as strongly that the subsequent trial will be reinforced. Alternatively, one could argue that the nonreinforced trials during acquisition with partial vs. continuous reinforcement resulted in a greater similarity between the acquisition and extinction 'contexts' (Capaldi, 1994). Since a return of responding after extinction may be weakened if extinction has been performed in a context more similar to the acquisition context (Bouton, 2002), this could explain why reacquisition is less rapid after partial reinforcement. While these effects on US expectancies seemed robust, no comparable effects were found for conditioned desires. Moreover, impulsivity seemed to affect reacquisition, although its interaction with measures of reacquisition was not consistent across the two studies. Future studies should replicate the present findings and attempt to match final levels of acquisition and extinction performance in order to conclude that reacquisition is indeed more rapid when preceded by CRF vs. PRF, and that impulsivity is related to differences in reacquisition.

The present studies provide unique evidence that partial reinforcement of food cues and, possibly, impulsiveness are related to worse extinction of appetitive responses to food cues. Further, it could be that partial reinforcement is associated with a less rapid reacquisition. These findings might have clinical implications. Cue exposure with response prevention is a treatment that aims to extinguish conditioned appetitive responses by repeated exposure to a conditioned cue (CS+) with response prevention, i.e., not eating, to prevent reinforcement. This extinction training is sometimes used to treat individuals with eating and/or weight disorders (Boutelle et al., 2011; Jansen, Broekmate, \& Heymans, 1992; Jansen, Havermans, \& Nederkoorn, 2011). The current data seem to predict that partially reinforced food cues will be more difficult to extinguish during cue exposure treatment. Similarly, our data suggest that dieters who attempt to extinguish responses to more partially (relative to more continuously) reinforced cues could experience more difficulty adhering to their diets. On the other hand, once extinction is achieved, previously partially reinforced food cues may reduce the strength of returns of appetitive responses (rapid reacquisition), improving long-term weight loss maintenance (for circumstantial evidence regarding a link between conditioned reactions to food cues and dieting success, see Jansen, Stegerman, Roefs, Nederkoorn, \& Havermans, 2010; see also Polivy, Herman, \& Coelho, 2008). It is of clinical interest to examine in future studies whether and to what extent weight loss success and/or maintenance can be attributed to specific learning histories and whether impulsivity plays a role.

In sum, the two studies combined are new in demonstrating a partial reinforcement extinction effect after appetitive condition- ing involving food rewards in healthy humans. This PREE was reflected in US expectancies and in the desire for food. Another new but preliminary finding was that impulsivity seemed to be related to a slower extinction of conditioned expectations to receive food. It is proposed that dieters who previously practised partial reinforcement of food cues experience PREEs during a diet, which could make (shorter-term) adherence to the diet more difficult. These individuals might however be at reduced risk for some forms of relapse once their responses have been successfully extinguished. Gaining more insight into the causes of individual differences in extinction and returns of appetitive responses might ultimately improve the successfulness of treatments aimed at achieving short- and longterm weight loss. Future research should aim to find out whether and in what ways short and long term dieting success can be predicted by differences in prior reinforcement schedules, and further clarify the roles of partial reinforcement and impulsivity in the acquisition, extinction, and reacquisition of appetitive responses to food cues.

\section{References}

Abad, M. J. F., Ramos-Álvarez, M. M., \& Rosas, J. M. (2009). Partial reinforcement and context switch effects in human predictive learning. The Quarterly Journal of Experimental Psychology, 62(1), 174-188. doi:10.1080/17470210701855561.

Amsel, A. (1962). Frustrative nonreward in partial reinforcement and discrimination learning. Some recent history and a theoretical extension. Psychological Review, 69, 306-328.

Avila, C., \& Parcet, M. A. (2000). The role of Gray's impulsivity in anxiety-mediated differences in resistance to extinction. European Journal of Personality, 14(3), 185-198. doi:10.1002/1099-0984(200005/06)14:3<185::AID-PER370>3.0.CO; 2-U.

Bish, C. L., Blanck, H. M., Serdula, M. K., Marcus, M., Kohl, H. W., \& Khan, L. K. (2005). Diet and physical activity behaviors among Americans trying to lose weight. 2000 behavioral risk factor surveillance system. Obesity, 13(3), 596-607.

Boddez, Y., Baeyens, F., Luyten, L., Vansteenwegen, D., Hermans, D., \& Beckers, T. (2013). Rating data are underrated. Validity of US expectancy in human fear conditioning. Journal of Behavior Therapy and Experimental Psychiatry, 44(2), 201-206. doi:10.1016/j.jbtep.2012.08.003.

Boggiano, M. M., Dorsey, J. R., Thomas, J. M., \& Murdaugh, D. L. (2009). The Pavlovian power of palatable food. Lessons for weight-loss adherence from a new rodent model of cue-induced overeating. International Journal of Obesity (2005), 33(6), 693-701.

Boutelle, K. N., Zucker, N. L., Peterson, C. B., Rydell, S. A., Cafri, G., \& Harnack, L. (2011). Two novel treatments to reduce overeating in overweight children. A randomized controlled trial. Journal of Consulting and Clinical Psychology, 79, 759-771.

Bouton, M. E. (2002). Context, ambiguity, and unlearning. Sources of relapse after behavioral extinction. Biological Psychiatry, 52(10), 976-986. doi:10.1016/s00063223(02)01546-9.

Bouton, M. E. (2007). Learning and behavior. A contemporary synthesis. Sunderland, MA: Sinauer Associates, Inc.

Bouton, M. E. (2011). Learning and the persistence of appetite. Extinction and the motivation to eat and overeat. Physiology and Behavior, 103(1), 51-58. doi:10.1016/j.physbeh.2010.11.025.

Bouton, M. E., \& Sunsay, C. (2003). Importance of trials versus accumulating time across trials in partially reinforced appetitive conditioning. Journal of Experimental Psychology. Animal Behavior Processes, 29(1), 62-77. doi:10.1037/00977403.29.1.62.

Bouton, M. E., Woods, A. M., \& Todd, T. P. (2014). Separation of time-based and trial-based accounts of the partial reinforcement extinction effect. Behavioural Processes, 101(0), 23-31. doi:10.1016/j.beproc.2013.08.006.

Butter, C. M. (1969). Perseveration in extinction and in discrimination reversal tasks following selective frontal ablations in Macaca mulatta. Physiology \& Behavior, 4(2), 163-171. doi:10.1016/0031-9384(69)90075-4.

Capaldi, E. J. (1994). The sequential view. From rapidly fading stimulus traces to the organization of memory and the abstract concept of number. Psychonomic Bulletin E' Review, 1(2), 156-181. doi:10.3758/bf03200771.

Corr, P. J. (2001). Testing problems in J. A. Gray's personality theory. A commentary on Matthews and Gilliland (1999). Personality and Individual Differences, 30(2), 333-352. doi:10.1016/S0191-8869(00)00028-3.

Corr, P. J. (2002). J. A. Gray's reinforcement sensitivity theory and frustrative nonreward. A theoretical note on expectancies in reactions to rewarding stimuli. Personality and Individual Differences, 32, 1247-1253.

Corr, P. J., Pickering, A. D., \& Gray, J. A. (1995). Personality and reinforcement in associative and instrumental learning. Personality and Individual Differences, 19(1), 47-71. doi:10.1016/0191-8869(95)00013-V.

Dawe, S., Gullo, M. J., \& Loxton, N. J. (2004). Reward drive and rash impulsiveness as dimensions of impulsivity. Implications for substance misuse. Addictive Behaviors, 29(7), 1389-1405. doi:10.1016/j.addbeh.2004.06.004. 
Doran, N., Spring, B., McChargue, D., Pergadia, M., \& Richmond, M. (2004). Impulsivity and smoking relapse. Nicotine \& Tobacco Research, 6(4), 641-647. doi:10.1080/ 14622200410001727939.

Field, A. E., Austin, S. B., Taylor, C. B., Malspeis, S., Rosner, B., Rockett, H. R., et al. (2003). Relation between dieting and weight change among preadolescents and adolescents. Pediatrics, 112(4), 900-906.

Franken, I. H., van Strien, J. W., Nijs, I., \& Muris, P. (2008). Impulsivity is associated with behavioral decision-making deficits. Psychiatry Research, 158(2), 155-163.

Gallagher, M., McMahan, R. W., \& Schoenbaum, G. (1999). Orbitofrontal cortex and representation of incentive value in associative learning. The Journal of Neuroscience, 19(15), 6610-6614.

Gorenstein, E. E., \& Newman, J. P. (1980). Disinhibitory psychopathology. A new perspective and a model for research. Psychological Review, 87, 301-315.

Guerrieri, R., Nederkoorn, C., \& Jansen, A. (2008). The effect of an impulsive personality on overeating and obesity. Current state of affairs. Psychological topics, 17, 265-286.

Gullo, M. J., Jackson, C. J., \& Dawe, S. (2010). Impulsivity and reversal learning in hazardous alcohol use. Personality and Individual Differences, 48(2), 123-127. doi:10.1016/j.paid.2009.09.006

Haselgrove, M., Aydin, A., \& Pearce, J. M. (2004). A partial reinforcement extinction effect despite equal rates of reinforcement during Pavlovian conditioning. Journal of Experimental Psychology. Animal Behavior Processes, 30, 240-250.

Hill, A. J. (2002). Prevalence and demographics of dieting. In C. G. Fairburn \& K. D. Brownell (Eds.), Eating disorders and obesity. A comprehensive handbook (2nd ed., pp. 80-83). New York: The Guilford Press.

Horn, N. R., Dolan, M., Elliott, R., Deakin, J. F. W., \& Woodruff, P. W. R. (2003). Response inhibition and impulsivity. An fMRI study. Neuropsychologia, 41(14), 1959-1966. doi:10.1016/S0028-3932(03)00077-0.

Houben, K., \& Jansen, A. (2011). Training inhibitory control. A recipe for resisting sweet temptations. Appetite, 56(2), 345-349. doi:10.1016/j.appet.2010.12.017.

Houben, K., Wiers, R. W., \& Jansen, A. (2011). Getting a grip on drinking behavior. Training working memory to reduce alcohol abuse. Psychological Science, 22(7), 968-975.

Jansen, A. (1998). A learning model of binge eating. Cue reactivity and cue exposure. Behaviour Research and Therapy, 36(3), 257-272. doi:10.1016/S00057967(98)00055-2.

Jansen, A., Broekmate, J., \& Heymans, M. (1992). Cue-exposure vs self-control in the treatment of binge eating. A pilot study. Behaviour Research and Therapy, 30(3), 235-241. doi:10.1016/0005-7967(92)90069-s.

Jansen, A., Havermans, R., \& Nederkoorn, C. (2011). Cued overeating. In V. R. Preedy, R. R. Watson, \& C. R. Martin (Eds.), Handbook of behaviour, food and nutrition. New York: Springer.

Jansen, A., Nederkoorn, C., van Baak, L., Keirse, C., Guerrieri, R., \& Havermans, R. (2009). High-restrained eaters only overeat when they are also impulsive. Behaviour Research and Therapy, 47(2), 105-110. doi:10.1016/j.brat.2008.10.016.

Jansen, A., Stegerman, S., Roefs, A., Nederkoorn, C., \& Havermans, R. (2010). Decreased salivation to food cues in formerly obese successful dieters. Psychotherapy and Psychosomatics, 79(4), 257-258.

Jeffery, R. W., Epstein, L. H., Wilson, G. T., Drewnowski, A., Stunkard, A. J., \& Wing, R. R. (2000). Long-term maintenance of weight loss. Current status. Health Psychology, 19(1, Suppl.), 5-16. doi:10.1037/0278-6133.19.Suppl1.5.

Kirk, S. F. L., \& Hill, A. J. (1997). Exploring the food beliefs and eating behaviour of successful and unsuccessful dieters. Journal of Human Nutrition and Dietetics, 10(6), 331-341. doi:10.1046/j.1365-277X.1997.00069.x.

Lasselin, J., Dexpert, S., Aubert, A., Beau, C., Ledaguenel, P., Magne, E., et al. (2013). 125. Adiposity-related low-grade inflammation and working memory alterations in obese patients before and after bariatric surgery. Brain, Behavior, and Immunity, 32(Suppl.), e36. doi:10.1016/j.bbi.2013.07.137.

Lovibond, P. F., \& Shanks, D. R. (2002). The role of awareness in Pavlovian conditioning. Empirical evidence and theoretical implications. Journal of Experimental Psychology. Animal Behavior Processes, 28(1), 3-26.

Lowe, M. R., \& Thomas, J. G. (2009). Measures of restrained eating: Conceptual evolution and psychometric update. In D. Allison \& M. L. Baskin (Eds.), Handbook of assessment methods for eating behaviors and weight related problems ( $\mathrm{pp}$. 137-185). New York: Sage.

Maayan, L., Hoogendoorn, C., Sweat, V., \& Convit, A. (2011). Disinhibited eating in obese adolescents is associated with orbitofrontal volume reductions and executive dysfunction. Obesity, 19(7), 1382-1387. doi:10.1038/oby.2011.15.

Mackintosh, N. J. (1974). The psychology of animal learning. London: Academic Press.
McDannald, M. A., Jones, J. L., Takahashi, Y. K., \& Schoenbaum, G. (2014). Learning theory. A driving force in understanding orbitofrontal function. Neurobiology of Learning and Memory, 108(0), 22-27. doi:10.1016/j.nlm.2013.06.003.

Morris, R. W., \& Bouton, M. E. (2006). Effect of unconditioned stimulus magnitude on the emergence of conditioned responding. Journal of Experimental Psychology. Animal Behavior Processes, 32(4), 371-385. doi:10.1037/0097-7403.32.4.371.

Nederkoorn, C., Jansen, E., Mulkens, S., \& Jansen, A. (2007). Impulsivity predicts treatment outcome in obese children. Behaviour Research and Therapy, 45(5), 1071-1075. doi:10.1016/j.brat.2006.05.009.

Neumark-Sztainer, D., Wall, M., Guo, J., Story, M., Haines, J., \& Eisenberg, M. (2006). Obesity, disordered eating, and eating disorders in a longitudinal study of adolescents. How do dieters fare 5 years later? Journal of the American Dietetic Association, 106(4), 559-568. doi:10.1016/j.jada.2006.01.003.

Papachristou, H., Nederkoorn, C., Beunen, S., \& Jansen, A. (2013). Dissection of appetitive conditioning. Does impulsivity play a role? Appetite, 69, 46-53.

Patterson, C. M., \& Newman, J. P. (1993). Reflectivity and learning from aversive events. Toward a psychological mechanism for the syndromes of disinhibition. Psychological Review, 100, 716-736.

Patton, J. H., Stanford, M. S., \& Barratt, E. S. (1995). Factor structure of the Barratt Impulsiveness Scale. Journal of Clinical Psychology, 51(6), 768-774. doi:10.1002 1097-4679(199511)51:6<768::AID-JCLP2270510607>3.0.CO;2-1.

Pittenger, D. J., \& Pavlik, W. B. (1988). Analysis of the partial reinforcement extinction effect in humans using absolute and relative comparisons of schedules. The American Journal of Psychology, 101(1), 1-14. doi:10.2307/1422789.

Polivy, J., Herman, C. P., \& Coelho, J. S. (2008). Caloric restriction in the presence of attractive food cues. External cues, eating, and weight. Physiology and Behavior, 94(5), 729-733. doi:10.1016/j.physbeh.2008.04.010.

Polivy, J., Herman, C. P., \& Howard, K. (1988). The restraint scale. Assessment of dieting. In M. Hersen \& S. Bellack (Eds.), Dictionary of behavioural assessment techniques (pp. 377-380). New York: Pergamon.

Ricker, S., \& Bouton, M. (1996). Reacquisition following extinction in appetitive conditioning. Animal Learning E' Behavior, 24(4), 423-436. doi:10.3758/ bf03199014.

Rolls, E. T. (2000). The orbitofrontal cortex and reward. Cerebral Cortex, 10, 284-294.

Rolls, E. T. (2004). The functions of the orbitofrontal cortex. Brain and Cognition, 55(1) 11-29. doi:10.1016/S0278-2626(03)00277-X.

Schafer, J. L., \& Graham, J. W. (2002). Missing data. Our view of the state of the art. Psychological Methods, 7(2), 147-177.

Schoenbaum, G., \& Esber, G. R. (2010). How do you (estimate you will) like them apples? Integration as a defining trait of orbitofrontal function. Current Opinion in Neurobiology, 20(2), 205-211.

Schoenbaum, G., Roesch, M. R., Stalnaker, T. A., \& Takahashi, Y. K. (2009). A new perspective on the role of the orbitofrontal cortex in adaptive behaviour. Nature Reviews. Neuroscience, 10(12), 885-892.

Stanford, M. S., Mathias, C. W., Dougherty, D. M., Lake, S. L., Anderson, N. E., \& Patton, J. H. (2009). Fifty years of the Barratt Impulsiveness Scale. An update and review. Personality and Individual Differences, 47(5), 385-395. doi:10.1016 j.paid.2009.04.008.

Stice, E., Presnell, K., Shaw, H., \& Rohde, P. (2005). Psychological and behavioral risk factors for obesity onset in adolescent girls. A prospective study. Journal of Consulting and Clinical Psychology, 73(2), 195-202. doi:10.1037/0022006x.73.2.195.

Tetley, A. C., Brunstrom, J. M., \& Griffiths, P. L. (2010). The role of sensitivity to reward and impulsivity in food-cue reactivity. Eating Behaviors, 11(3), 138-143. doi:10.1016/j.eatbeh.2009.12.004.

van den Akker, K., Jansen, A., Frentz, F., \& Havermans, R. C. (2013). Impulsivity makes more susceptible to overeating after contextual appetitive conditioning. Appetite, $70,73-80$.

van Koningsbruggen, G. M., Stroebe, W., \& Aarts, H. (2013). Successful restrained eating and trait impulsiveness. Appetite, 60(1), 81-84

Van Gucht, D., Baeyens, F., Vansteenwegen, D., Hermans, D., \& Beckers, T. (2010). Counterconditioning reduces cue-induced craving and actual cue-elicited consumption. Emotion (Washington, D.C.), 10(5), 688-695. doi:10.1037/a0019463.

Van Gucht, D, Vansteenwegen, D. Beckers, T, \& Van den Bergh, O. (2008). Return of experimentally induced chocolate craving after extinction in a different context Divergence between craving for and expecting to eat chocolate. Behaviour Research and Therapy, 46(3), 375-391. doi:10.1016/j.brat.2008.01.003.

Verbeken, S., Braet, C., Goossens, L., \& van der Oord, S. (2013). Executive function training with game elements for obese children. A novel treatment to enhance self-regulatory abilities for weight-control. Behaviour Research and Therapy, 51(6), 290-299. doi:10.1016/j.brat.2013.02.006. 